\title{
The Moderator Role of Gender and Socioeconomic Status in the Relationship Between Metacognitive Skills and Reading Scores
}

\author{
İlhan KOYUNCU* \\ Department of Educational Sciences, Adiyaman University, Turkey \\ ORCID: 0000-0002-0009-5279 \\ Metin BULUŞ \\ Department of Educational Sciences, Adlyaman University, Adlyaman, Turkey \\ ORCID: 0000-0003-4348-6322
}

\section{Tahsin FIRAT}

Department of Special Education, Adlyaman University, Adlyaman, Turkey ORCID: 0000-0002-3577-7907

Article history

Received:

25.05.2021

Received in revised form: 23.09.2021

Accepted:

06.10.2021

Key words:

Moderator effect;

Multi-group structural equation modelling;

Metacognition;

Reading achievement; PISA
The aim of this study was to examine the moderator role of gender and socioeconomic status (SES) factors in the relationship between students' metacognitive skills and reading performance. The sample of the study was 6890 students in the age group of 15 years-old who participated in the Programme for International Student Assessment (PISA) in 2018 from Turkey. 3396 of the participants $(49.30 \%)$ were female and 3494 $(50.70 \%)$ of them were male. Of the participants, 2273 (32.99\%) were classified as low, 2273 (32.99\%) as medium and 2344 (34.02\%) as high socioeconomic level. Moderator effects were tested with the multi-group structural equation modelling approach. Results revealed that SES and gender moderated the relationship between metacognitive skills and reading when controlling for other variables. Female students scored lower than male students in low and medium SES group, however they scored higher in the high SES group even after controlling for metacognitive skills, liking reading, and self-concept of perception of competence and difficulty. This means gender differences in reading scores were largely driven by SES. Therefore, the effect of these two factors should be taken into consideration while working on metacognition and reading. Moreover, it was advised to integrate training of metacognitive strategies in school curriculum and encourage reading engagement in order to reduce the effect of those factors.

\section{Introduction}

Written symbols need to be analysed and interpreted by the reader to acquire reading skills (Sideridis, Mouzaki, Simos, \& Protopapas, 2006). In the first few years of the primary school, one of the goals of the formal education is to have students acquire word decoding and fluent reading skills. By the fourth and fifth grade, students are expected to use reading as

\footnotetext{
*Correspondency: ilhankync@gmail.com
} 
a tool to achieve academic learning in other fields (Best, Floyd, \& Mcnamara, 2008; Kim, Linan-Thompson, \& Misquitta 2012; Wanzek, Vaughn, Scammacca, Metz, Murray, Roberts, \& Danielson, 2013). In other words, "learning to read" is emphasized for students in the first few years of the school, while "reading to learn" is emphasized in the following years (van Bergen, Vasalampi, \& Torppa, 2020; Wharton-McDonald \& Erickson, 2017). Despite intensive education, many children and adolescents fail to reach functional levels of reading comprehension (Kendeou, Van Den Broek, Helder, \& Karlsson, 2014) because reading is a complex process that requires the use of many cognitive and non-cognitive skills (Calet, López-Reyes, \& Jiménez-Fernández, 2020; van den Broek \& Espin, 2012).

Since 2000, the Programme for International Student Assessment (PISA) conducted by the Organisation for Economic Co-operation and Development (OECD) provided an opportunity to study and reveal factors affecting reading performance of the 15 -year-old students. Metacognition is one of the most important factors that predicts reading performance (Koyuncu \& Frrat, 2020; Säälik, Nissinen, \& Malin, 2015). In addition, gender and socioeconomic status (SES) are two demographic variables that are of interest to education policy and practice. While there is burgeoning evidence on gender (Rajchert, Żułtak, \& Smulczyk, 2014) and SES reading gaps (Rogiers, Van Keer, \& Merchie, 2020; VázquezCano, la Calle-Cabrera, María, Hervás-Gómez, \& López-Meneses, 2020), emerging research demonstrates that gender and SES groups utilize metacognition strategies differently (Callan, Marchant, Finch, \& German, 2017; Chuy \& Nitulescu, 2013, Lee \& Wu, 2013; Wu, 2014). The goal of this study is to explore whether some of the gender and SES gaps can be attributed to metacognitive skills. Thus, this study investigates whether gender and SES moderate the relationship between metacognitive skills and reading scores.

\section{The role of metacognition}

Metacognition was first defined by Flavell as being aware of one's own thinking processes and being able to control these processes (Flavell, 1979). Although the information on metacognition dates to about 40 years ago, this subject is still up to date. As a matter of fact, metacognition has found an important place in PISA studies in recent years. In PISA, metacognition was included under the headings of summarizing (METASUM), and understanding and remembering (UNDREM) in 2009, while evaluating the credibility of knowledge (METASPAM) was added in 2018 (OECD, 2019). In many studies based on using PISA data, metacognition emerged as an important predictor of reading performance (Artelt, Schiefele, \& Schneider, 2001; Callan, Marchant, Finch, \& German, 2016; Chiu, Chow, \& Mcbride-Chang, 2007; Säälik, 2015). Säälik et al. (2015) found that metacognition has the strongest explanatory power in explaining the differences in reading achievement in each country at both school and student levels. Koyuncu and Firat (2020) found metacognition is an important predictor of reading success for Chinese, Turkish, and Mexican students which have different levels of success in PISA 2018. These results highlight the importance of detailing the relationship between metacognition and reading success. Reading success is the competence in the process starting from recognizing the sounds and understanding the message given in the text. On the other hand, one reason why many students have difficulty in understanding what they read is the inadequacy of metacognitive strategies that support students' reading comprehension (McHardy, Chapman, \& O'Neill, 2021; Mokhtari \& Reichard, 2002).

Metacognition in reading is expressed as the ability to recognize and use appropriate strategies to understand the text (OECD, 2010). In other words, the selection of strategies 
required for reading comprehension and why, when, and how they should be used is closely related to metacognition (Mokhtari \& Reichard, 2002). Thus, metacognition includes knowledge of comprehension strategies (that is, good readers' knowledge of knowing what they guess, creating images that represent ideas encountered in the text, and summarizing what they read) as well as strategy knowledge that good readers consciously use (Pressley, 2002). In particular, good readers monitor and evaluate the reading process, and organize reading methods to achieve reading goals ( $\mathrm{Wu}, 2014)$.

Conscious use of metacognitive strategies while reading helps the reader to understand relevant information in a text, activate past knowledge, and follow and organize learning strategies to improve understanding (Kolić-Vehovec, Rončević Zubković, \& Pahljina-Reinić, 2014). In this context, metacognitive strategies enable students to think more carefully and systematically while reading. In addition, metacognitive strategies enable students to participate actively in the reading process by improving their critical thinking skills (Sencibaugh, 2007). Therefore, students with metacognitive strategy knowledge pay attention to reading processes and become good readers. As a matter of fact, many studies have determined that successful readers use more metacognitive strategies than poor readers (Anastasiou \& Griva, 2009; Fırat \& Koçak, 2019; Hong-Nam \& Leavell, 2007; Houtveen \& Van de Grift, 2007; Lau, 2006; Lau \& Chan, 2003).

\section{The role of gender}

Debate on gender differences in education continues in most OECD countries (Marks, 2008). The relationship between gender and reading performance in PISA studies is one of the most curious issues. Girls are more successful in reading than boys in most of the studies (Lynn \& Mikk, 2009; Rogiers et al., 2020; Solheim \& Lundetræ, 2018). This difference is often attributed to social changes in attitudes towards equal opportunities for men and women, reading enjoyment and motivation (Chiu \& McBride-Chang, 2006; Rajchert et al., 2014; Rogiers et al., 2020; Stoet \& Geary, 2013). Moreover, some studies show that men are more prone to reading difficulties (Moll, Kunze, Neuhoff, Bruder, \& Schulte-Körne, 2014; Rutter et al., 2004). Conversely, Torppa, Eklund, Sulkunen, Niemi, and Ahonen (2018) found that girls and boys (except fluent reading) show similar reading performance. Gender differences in the selection of metacognitive strategies can help explain the advantages of girls in reading comprehension $(\mathrm{Wu}, 2014)$. On the other hand, while there are some studies showing that girls use metacognitive strategies more effectively than boys (Callan et al., 2016; Chuy \& Nitulescu, 2013; Mak, Cheung, Soh, Sit, \& Ieong, 2017), no difference was found in a limited number of studies (Bembenutty, 2007). Chuy and Nitulescu (2013), using Canada PISA 2009 data, found that girls compared to boys (i) read more diverse and enjoy reading in general, (ii) use control and memorization strategies more frequently, and (iii) were more aware of the most effective metacognitive strategies.

\section{The role of $S E S$}

As the student population increasingly become diverse, understanding the relationship between students' socioeconomic backgrounds and their reading behaviour and performance is more challenging than ever (Rogiers et al., 2020). In PISA studies, SES is handled within the framework of student and school level variables. The variables considered at the student level are mother's education level, father's education level and home facilities. At the school level, teacher qualification, place of residence, number of activities organized at school, student-teacher ratio, school type, educational resources and family participation variables draws attention (OECD, 2018). When studies using PISA data are examined, the education 
levels of the mother and father (Gülleroğlu, Bilican, \& Demirtaşl1, 2014; İnce \& Gözütok, 2018; Kotte, Lietz, \& Lopez, 2005; Vázquez-Cano et al., 2020), the student's home resources (Gülleroğlu et al., 2014; İnce \& Gözütok, 2018; Shala \& Grajcevci, 2018) and school type (Rajchert et al., 2014; Rogiers et al., 2020) were found to be effective factors on reading performance.

In addition, students in different levels of SES utilized metacognitive strategies to varying degrees (Akyol, Sungur, \& Tekkaya, 2010; Callan et al., 2016). Lee and Wu (2013) found that students' SES were associated with reading literacy scores and metacognitive strategy preference. Also, students in higher socioeconomic levels had better learning outcomes and had better use of metacognitive strategies. Callan et al. (2016) found that not only did students from higher SES countries use metacognitive strategies more frequently, but even after controlling for individual SES, metacognitive strategies were more strongly associated with higher achievement in higher SES countries. Callan et al. (2017) determined that family SES, school SES, and metacognitive strategies are positively associated with the reading success. In addition, going to schools with higher SES as well as being female was associated with the use of more adaptive strategies and students from higher SES families tended to use all types of strategies more. In the light of those studies, considering the significant effect of SES on metacognition and reading, it would be appropriate to evaluate factors affecting students' reading success after controlling for the SES.

Metacognition is believed to be amongst one of the most important factors that predict students' reading performance (Artelt, Schiefele, \& Schneider, 2001; Callan et al., 2016; Chiu, Chow, \& Mcbride-Chang, 2007; Säälik, 2015). In addition, the gender and SES of students are other important predictors of reading. Literature also established that students may utilize metacognitive strategies to varying degree depending on their gender and SES level.

\section{Aim of the study}

The aim of this study is to examine the moderator role of gender and SES on the relationship between metacognition skills and reading performance. In this context, answers to the following research problems have been sought:

(1) Does SES moderate the relationship between metacognitive skills and reading scores while controlling for gender and other important factors?

(2) Does gender moderate the relationship between metacognitive skills and reading scores while controlling for SES and other important factors?

\section{Method}

In this section, the research design, participants, data collection tools and data analysis are presented below under separate subheadings.

\section{Research design}

This quantitative study aims to examine the role of students' gender and socioeconomic levels in the relationship between metacognition and reading. This study is a correlational study since the relationships between variables are examined by controlling the effects of the other variables. In correlational studies, it is aimed to discover the relationships between variables using quantitative data (Fraenkel \& Wallen, 2006). 


\section{Participants}

The sample group of the study is 6890 students, in the 15 years-old age group, who participated in the PISA 2018 study from Turkey. Participants were selected by PISA practitioners through stratified random sampling. 3396 of the participants (49.3\%) are female and $3494(50.7 \%)$ of them are male. Of the participants, $2273(32.99 \%)$ were classified as low, $2273(32.99 \%)$ as medium and $2344(34.02 \%)$ as high socioeconomic level.

\section{Data collection}

In this study, variables in the student questionnaires and reading cognitive tests in the PISA 2018 were used. Index of economic, social, and cultural status (ESCS) is a combination of highest parental occupational status, highest parental educational status, and home possessions variables in the student questionnaire. The variable is referred as SES in the introduction and discussion sections of the present study. Metacognition latent variable is defined based on understanding and remembering (UNDREM), summarizing (METASUM) and assess credibility (METASPAM) scales. The scores of those scales were obtained by scoring the answers given by the students to the questions related to their metacognitive strategy preference. Self-concept of reading latent variable is defined with perception of competence (SCCOMP) and perception of difficulty (SCDIFF) variables. Joy/Like reading (JOYREAD) scale consists of 5 items. In the PISA student questionnaire, attitudes, motivation, and strategies were included in Module 4 under non-cognitive and metacognitive constructs (OECD, 2019).

In the cognitive dimension, there are overall reading and reading subscale scores. Reading cognitive process subscales consist of Locate Information (RCLI), Understand (RCUN) and Evaluate and Reflect (RCER) scale scores. There are Single (RTSN) and Multiple (RTML) subscales for Text Structure Subscale. Ten plausible values representing overall reading and subscales were calculated for each student. Plausible values are scores that are randomly selected from the posterior distribution of students' ability scores estimated based on item response theory (OECD, n.d.).

\section{Data analysis}

The multi-group structural equation modelling (MG-SEM) is a common approach to investigate differential effects of categorical or ordinal moderators (Memon et al., 2019). In this study, MG-SEM approach was used to test whether gender and ESCS moderates the relationship between metacognitive skills and reading scores. MG-SEM approach to moderation analysis provides a flexible and robust framework to test differential effects. This approach allows to model latent variables, measurement errors, and specify covariance between them. The MLR (maximum likelihood estimation with robust standard errors) estimation in conjunction with TYPE $=$ COMPLEX was used in Mplus 7 (Muthern \& Muthen, 2012) assuming that all indicators are continuous (scale scores provided by PISA). Cluster and stratification information was considered, and standard errors that consider these specifications are based on quasi-pseudo maximum likelihood (Asparouhov, 2005; Asparouhov \& Muthén, 2010; Stapleton, 2008). Survey weights were also included for generalizable results and 10 plausible values were considered for the reading scores. MLR estimation can also handle missing data. Instead of imputing the data, MLR estimate was allowed to handle it because maximum likelihood-based estimates under missing values can be more efficient than multiple imputation-based estimates, especially with large sample sizes (Yuan, Yang-Wallentin, \& Bentler, 2012). 


\section{Measurement models}

First, it was started with establishing and refining measurement models. Three separate measurement models were investigated for each scale using the MG-SEM approach. Measurement invariance properties of the scales should be investigated before embarking on a multi-group analysis. For each scale, configural invariance model (all parameters are free across subgroups), metric invariance model (loadings are constrained to be same across subgroups), and scalar invariance model (loadings and intercepts are constrained to be same across subgroups) were investigated. Chen (2008) suggests that a $\Delta$ CFI value deterioration less than .010 and/or $\triangle$ RMSEA value of .015 between measurement models favors the more parsimonious model (with more constraints) when investigating scalar invariance. When this rule was not satisfied but the model fit for the more parsimonious model was good, the parsimonious model was favored considering higher subgroup reliability estimates. For subgroup reliability estimates McDonald's $\omega$ and Maximal Reliability $(\mathrm{H})$ was computed (Geldhof, Precher, \& Zyphur, 2014).

Table 1. Scale fit indices and subgroup reliability estimates for retained measurement models.

\begin{tabular}{|c|c|c|c|c|c|c|c|}
\hline & & & 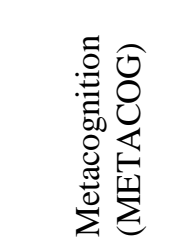 & 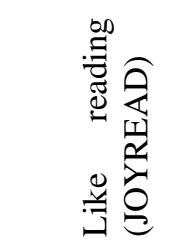 & 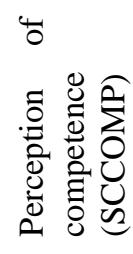 & 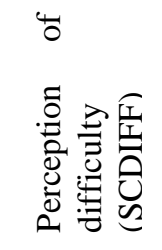 & 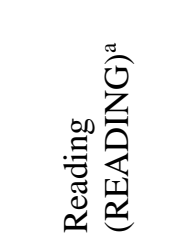 \\
\hline \multirow{9}{*}{$\begin{array}{l}\overline{\bar{v}} \\
\bar{D} \\
\stackrel{0}{0}\end{array}$} & \multirow{7}{*}{ McDonald's $\omega$} & $\chi^{2}$ & $19.561 * * *$ & $221.931 * * *$ & \multicolumn{2}{|c|}{$733.073 * * *$} & $1793.56 * * *$ \\
\hline & & $\chi^{2}$ d.f. & 3 & 15 & \multicolumn{2}{|c|}{28} & 17 \\
\hline & & RMSEA & .04 & .06 & \multicolumn{2}{|l|}{.09} & .17 \\
\hline & & CFI & .99 & .95 & \multicolumn{2}{|l|}{.89} & .99 \\
\hline & & TLI & .98 & .94 & \multicolumn{2}{|l|}{.88} & .99 \\
\hline & & Male & .74 & .82 & .78 & .69 & .98 \\
\hline & & Female & .74 & .87 & .82 & .70 & .98 \\
\hline & \multirow{2}{*}{ Maximal H } & Male & .76 & .83 & .79 & .70 & .99 \\
\hline & & Female & .76 & .88 & .82 & .73 & .99 \\
\hline \multirow{11}{*}{$\begin{array}{l}\tilde{U} \\
\tilde{U}\end{array}$} & & $\chi^{2}$ & $51.50 * * *$ & $102.80 * * *$ & \multicolumn{2}{|c|}{$417.72 * * *$} & $2000.01 * * *$ \\
\hline & & $\chi^{2}$ d.f. & 7 & 32 & \multicolumn{2}{|c|}{48} & 30 \\
\hline & & RMSEA & .05 & .03 & \multicolumn{2}{|l|}{.06} & .17 \\
\hline & & CFI & .98 & .99 & \multirow{2}{*}{\multicolumn{2}{|c|}{$\begin{array}{l}.94 \\
.95\end{array}$}} & .97 \\
\hline & & TLI & .97 & .99 & & & .97 \\
\hline & \multirow{3}{*}{ McDonald's $\omega$} & Low ESCS & .75 & .76 & .79 & .69 & .99 \\
\hline & & Medium ESCS & .76 & .76 & .80 & .69 & .99 \\
\hline & & High ESCS & .76 & .78 & .80 & .71 & .98 \\
\hline & \multirow{3}{*}{ Maximal H } & Low ESCS & .77 & .78 & .79 & .71 & .99 \\
\hline & & Medium ESCS & .78 & .78 & .80 & .71 & .99 \\
\hline & & High ESCS & .79 & .80 & .80 & .72 & .99 \\
\hline
\end{tabular}

Table 1 provides fit indices and subgroup reliability estimates for retained measurement models. Scalar invariance model was retained for METAGOC and JOYREAD scales both for gender and ESCS models, because they both had good model fits and higher subgroup reliability estimates. For SCCOMP and SCDIFF scales (inspected in the same model with covariance between them), scalar invariance model was retained for gender model, however, metric invariance model was retained for the ESCS model based on acceptable model fit 
indices and higher subgroup reliability estimates. The scalar invariance model was retained for the READING scale; however, it should be noted that conventional model fit indices are not reliable with plausible values (see Enders \& Mansolf, 2018; Mansolf, Jorgensen, \& Enders, 2020). Nonetheless, the reading scale has high CFI and TLI values and high subgroup reliability estimates.

\section{Structural models}

Structural model was specified with retained measurement models as in Figure 1. Reading subscales (RCLI, RCUN, RCER, RTSN, and RTML) were re-scaled to overcome convergence issues (scores divided by 100). Depending on the moderation analysis either Gender or ESCS was included as covariate. When gender subgroups were of interest for the MG-SEM, ESCS (continuous composite index scores) was included as covariate, and when ESCS subgroups were of interest the gender variable was included as covariate. There are important factors which predicts reading performance such as enjoyment of reading (JOYREAD; Koyuncu \& Firat, 2020; Chiu \& McBride-Chang, 2006; Lau \& Ho, 2016) and self-concept of reading (SCCOMP and SCDIFF; Roeschl-Heils, Schneider, \& van Kraayenoord, 2003; Van Kraayenoord \& Schneider, 1999). For this reason, these three variables were also added to the model as covariates. For the JOYREAD scale, we specified covariance between residuals for indicator JOYR2 and JOYR3 because these two items had positive valance in comparison to the remaining items (reverse coded). Errors of the reverse coded items tend to be correlated, thus, drawing covariance between them is justifiable (Brown, 2015). Literature suggests that METACOG and JOYREAD scales are correlated, indeed they are listed under the same module during the PISA survey administration. Thus, covariance between METACOG and JOYREAD scales was specified. SCCOMP and SCDIFF scales belong to the same overarching self-concept scale, thus they have covariance between them. Means of the scales were estimated, while variance of the scales in the reference groups were constrained to the unity for identification purposes. 


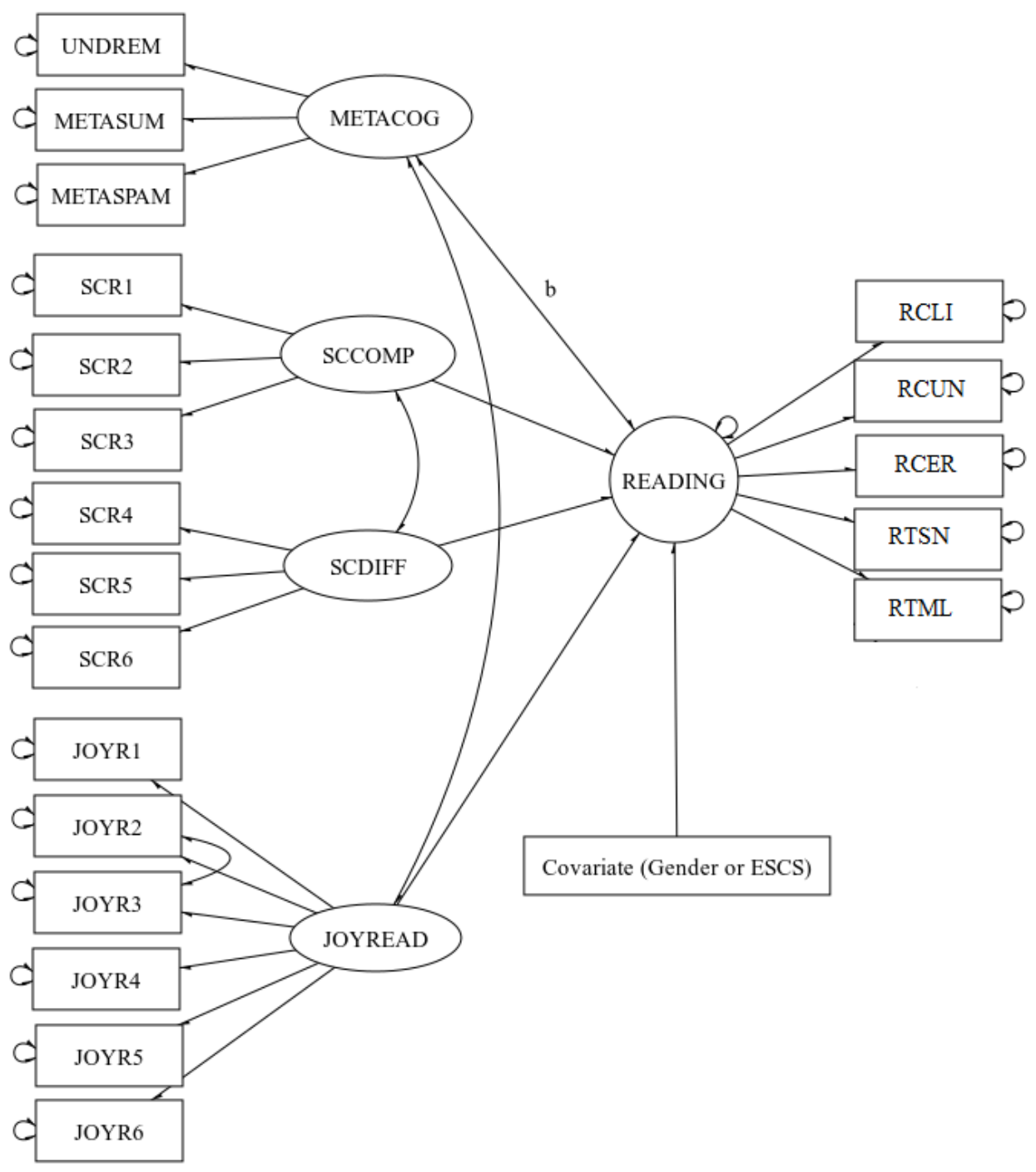

Figure 1. Structural model to test whether path b differs across Gender (Female - Male) and ESCS (Low - Medium - High) subgroups.

Essentially, in this study, it was interested in whether path $b$ (see Figure 1) differs across gender and ESCS subgroups. A meaningful difference across subgroups indicates moderation effect. Three MG-SEM models were run: (i) ESCS (low - medium - high), (ii) gender (female - male), and (iii) an overall model based on the whole dataset. ESCS groups are created based on tertiles of the continuous composite index scores for multigroup analysis, however, the continuous scale is used when ESCS is included as a covariate. Decision to split data into three groups for the ESCS group was based on the visual inspection of the plots and our own experience with ESCS variable. ESCS tend to follow a curvilinear trend with academic achievement. Splitting data into two raises the possibility of masking effect. In fact, both two groups and three groups were tried. While a moderation with two groups was not detected, moderation with three groups was detected (coefficients obtained for three groups indeed suggest that there is a curvilinear trend).

\section{Findings}

Several interesting trends surface as a result of this study. The key finding is that ESCS and gender moderates the relationship between metacognitive skills and reading. In all 
subgroups and overall, metacognitive skill is strongly related to the reading scores (see Table 2 ), but coefficients differentiate for subgroups $(\beta$ ranges from .49 to .66 , all $p<.001)$ after controlling for other factors. The high ESCS group has stronger relationship between the metacognitive skills and the reading scores in comparison to the medium ESCS group (std. difference: $\beta=.09, p<.010$ ), whereas other comparisons produce weak evidence of difference (see Table 3). This means, hypothetically, moving an average student from medium ESCS to high ESCS group could potentially bump his/her reading score up by 3.63 percentile points due to stronger relationship between metacognitive skills and reading ability.

Table 2. Structural coefficients for multi-group and overall SEM models.

\begin{tabular}{|c|c|c|c|c|c|c|c|c|}
\hline & & & Low & & Medium & & High & \\
\hline & & & Est. (SE) & Std. $\beta$ & Est. (SE) & Std. $\beta$ & Est. (SE) & $\beta$ \\
\hline ESCS & & $\begin{array}{l}\text { Metacognition } \\
\text { (METACOG) }\end{array}$ & $.78(.05)^{* * *}$ & .64 & $.69(.05)^{* * *}$ & .59 & $.87(.06)^{* * *}$ & .58 \\
\hline & $\begin{array}{l}= \\
=\end{array}$ & $\begin{array}{ll}\text { Like } & \text { reading } \\
(\text { JOYREAD) } & \end{array}$ & $-.01(.04)$ & -.04 & $-02(04)$ & -04 & $-11(05) *$ & -04 \\
\hline TLI = .89) & & $\begin{array}{l}\text { Perception of } \\
\text { competence (SCCOMP) }\end{array}$ & $.08(.04)^{+}$ & .07 & $.08(.04)^{*}$ & .06 & $.09(.04)^{*}$ & .06 \\
\hline & & $\begin{array}{l}\text { Perception of difficulty } \\
\text { (SCDIFF) }\end{array}$ & $-.26(.04) * * *$ & -.20 & $-.18(.04)^{* * *}$ & -.15 & $-.17(.04)^{* * *}$ & -.12 \\
\hline & & Gender (GENDER) & $-.35(.09) * * *$ & $-.12^{+}$ & $-.12(.07)^{+}$ & -.04 & $.41(.06) * * *$ & .16 \\
\hline & & $R^{2}$ & .42 & & .34 & & .44 & \\
\hline & & & Female & & Male & & & \\
\hline & & & Est. (SE) & Std. $\beta$ & Est. (SE) & Std. $\beta$ & & \\
\hline Gender & & $\begin{array}{l}\text { Metacognition } \\
\text { (METACOG) }\end{array}$ & $.68(.02)^{* * *}$ & .66 & $.55(.03)^{* * *}$ & .49 & & \\
\hline $\begin{array}{l}\text { (RMSEA } \\
.08, \quad \text { CFI }\end{array}$ & $\begin{array}{l}= \\
=\end{array}$ & Like $\quad$ reading & $-.03(.03)$ & -.03 & $-.02(.03)$ & -.02 & & \\
\hline $\begin{array}{l}.90, \\
\text { TLI }=.89)\end{array}$ & & Perception of & $.06(.03)^{*}$ & .05 & $.07(.03)^{*}$ & .06 & & \\
\hline & & $\begin{array}{l}\text { Perception of difficulty } \\
\text { (SCDIFF) }\end{array}$ & $-.14(.04)^{* * *}$ & -.11 & $-.21(.03)^{* * *}$ & -.18 & & \\
\hline & & ESCS & $.19(.02) * * *$ & .29 & $.23(.02)^{* * *}$ & .31 & & \\
\hline & & $R^{2}$ & .52 & & .37 & & & \\
\hline & & & Est. (SE) & Std. $\beta$ & & & & \\
\hline & & $\begin{array}{l}\text { Metacognition } \\
\text { (METACOG) }\end{array}$ & $.86(.05)^{* * *}$ & .57 & & & & \\
\hline Overall & & $\begin{array}{ll}\text { Like } & \text { reading } \\
(\text { JOYREAD) }\end{array}$ & $-.03(.03)$ & -.03 & & & & \\
\hline $\begin{array}{l}\text { (RMSEA } \\
.08, \quad \text { CFI } \\
.90, \\
\text { TLI }=.88)\end{array}$ & $\begin{array}{l}= \\
=\end{array}$ & $\begin{array}{l}\text { Perception of } \\
\text { competence (SCCOMP) } \\
\text { Perception of difficulty } \\
\text { (SCDIFF) }\end{array}$ & $\begin{array}{l}.06(.02)^{* * *} \\
-.22(.03) * * *\end{array}$ & $\begin{array}{l}.05 \\
-.15\end{array}$ & & & & \\
\hline & & ESCS & $.21(.02)^{* * *}$ & .30 & & & & \\
\hline & & Gender (GENDER) & $.01(.04)$ & .01 & & & & \\
\hline & & $R^{2}$ & .44 & & & & & \\
\hline
\end{tabular}

Note. ${ }^{+} p<.10 ;{ }^{*} p<.05 ;{ }^{* *} p<.01 ;{ }^{* * *} p<.001$. Est.: Estimate. Std.: Standardized. SE: Standard Error (in parenthesis). Fit indices are obtained from average of 10 plausible values. Conventional fit indices are not reliable with plausible values. GENDER: $0=$ Male and $1=$ Female.

Gender also serves as a moderator. The female group has stronger relationship between metacognitive skills and reading in comparison to the male group (std. difference: $\beta=.14, p$ $<.010$ ). This means, hypothetically, had an average male student been female, he could have an advantage of 6.70 percentile points over his peers due to a stronger relationship between the metacognitive skills and the reading scores. 
Table 3. Differential effects of metacognitive skills on reading

\begin{tabular}{lllll}
\hline Moderator & Group Comparison & Est. $(S E)$ & Std. $\beta$ & Percentile Difference \\
\hline \multirow{3}{*}{ ESCS } & High - Medium & $.18(.06)^{* *}$ & .09 & 3.63 \\
& High - Low & $.10(.07)$ & .06 & 2.52 \\
& Medium - Low & $-.08(.05)$ & .03 & 1.12 \\
\hline Gender & Female - Male & $.14(.04)^{* *}$ & .17 & 6.70 \\
\hline
\end{tabular}

Note. ${ }^{* *} p<.010$ based on Wald test of difference (Loglikelihood difference goodness of fit test for model comparisons - between unconstrained and constrained models - are not reliable with plausible values). Est.: Estimate. Std.: Standardized. SE: Standard Error (in parenthesis). Percentile difference refers to the potential increase (or decrease) of an average student's performance by X percentile points as a result of differential effect.

There are other interesting findings. Female students score lower than male students in low and medium ESCS group ( $\beta=-.12, p<.001$ and $\beta=-.04, p<.100$, respectively), however they score higher in the high ESCS group $(\beta=.16, p<.001)$ even after controlling for metacognitive skills, liking reading, and self-concept of perception of competence and difficulty. This means gender differences in reading scores are largely driven by the ESCS. Analyzed together, in the overall model (see Table 2), gender differences diminish after controlling for other factors.

Perception of difficulty is negatively associated with the reading scores, in all subgroups $(\beta$ ranges from -.12 to -.20 , all $\mathrm{p}<.001)$ and overall $(\beta=-.22, p<.001)$. This relationship is stronger than the positive association between the perception of competence and the reading scores $(\beta$ around .06 , mostly $p<.050)$. Strangely, liking reading tends to be negatively associated with the reading scores, and only statistically significant in the high ESCS group $(\beta=-.04, p<.050)$.

Proportion of explained variance by the model hovers around moderate effect per Cohen's (1988) guideline. Nonetheless, these effects are differential across subgroups. Proportion of variance in the reading scores explained by the model is $42 \%$ in the low ESCS group, $34 \%$ in the medium ESCS group and $44 \%$ in the high ESCS group. As for the gender, proportion of explained variance is $52 \%$ for the female group whereas it is $37 \%$ in the male group. In the overall model, the proportion of explained variance is $44 \%$.

\section{Discussion}

In this study, the effect of gender and SES on the relationship between students' metacognitive skills and reading skills was examined. In addition, reading self-concept and reading enjoyment variables, which have a high level of predictive power on PISA reading performance, were also added to the models as covariates.

This study reveals that the relationship between metacognition and reading differentiates according to the gender after controlling for other factors. Accordingly, the relationship between the metacognitive skills and reading performance is stronger for female students than it is for male students. Besides, the total explained variance of the model for female students is higher than that of males. In general, models have moderate effects according to Cohen's (1988) guideline. This result highlights the importance of gender differences in the effect of metacognitive factors on reading performance. In a study conducted with PISA 2009 data, when the socioeconomic level is controlled, girls show higher reading performance than boys and this situation is mostly explained by reading engagement factors such as reading enjoyment and metacognitive factors (Mak et al., 2017). Lynn and Mikk (2009) examined PISA and PIRLS studies and found that girls' reading performances were higher than boys 
due to their active participation in reading activities.

In addition, Chiu and McBride-Chang (2006) compared reading performances of students from 43 countries and showed that girls had higher reading scores than boys, and reading pleasure mediated this relationship to a large extent. In order to explain this situation, Lynn and Mikk (2009) stated that girls read more at home and at school, while boys are busy with computers or technological tools. Indeed, when it comes to digital reading, boys' higher performance than girls' (Lim \& Jung, 2019) supports this opinion of Lynn and Mikk (2009). Girls reads a lot of books at home and at school which leads to the development of their metacognitive skills and their overall higher performance in reading. Therefore, encouraging males to participate in reading activities could possibly contribute to the development of metacognitive skills, which in turn, could bump their reading scores up and consequently reduce the gender gap.

Furthermore, girls use metacognitive strategies more than boys (Callan et al., 2016; Sheorey \& Mokhtari, 2001; Wu, 2014) which leads to higher overall reading success. In this context, training and encouraging males about learning and using metacognitive strategies could possibly reduce the gender gap because metacognitive strategy knowledge significantly predicts reading success ( $\mathrm{Wu} \&$ Peng, 2017). According to the OECD report, learning metacognitive strategies tend to mediate gender differences in reading performance, and reading performance could be increased by 15 points if boys had the same level of metacognitive skills as girls (OECD, 2010). According to Mak et al. (2017), male students especially (1) should be taught to use effective metacognitive reading strategies, (2) should be encouraged to read more broadly, and (3) they should be guided to enjoy reading materials to the same extent as their female peers.

According to the results of this study, the relationship between metacognition and reading differentiates according to the socioeconomic levels of the students when the effects of other factors are controlled. Accordingly, in high SES group, metacognition skills of students were more strongly associated with reading performance than intermediate level students. In general, the model has a moderate effect according to Cohen's (1988) guideline. Thus, results highlight the importance of considering the SES factor while examining the effect of metacognition on reading. Students in high SES group use metacognitive strategies more compared to low SES group which leads to higher reading success (Callan et al., 2016; Wu, 2014). Callan et al. (2016) found that students in countries with high SES levels prefer metacognitive strategies more often than students in countries with low SES levels. In parallel, students in countries with high SES levels are significantly higher in reading performance than students in other countries.

However, when gender, cognition-related and information and communication technologies (ICT) variables were controlled, SES level was not a significant predictor for digital reading (Lim \& Jung, 2019). The fact that males can obtain higher scores than females in digital reading indicates that the gender factor together with SES has a different effect on reading scores. Similarly, in high SES group, this study demonstrates that female students perform superior in reading compared to male students. This shows that girls are more affected by socioeconomic factors than boys in terms of reading success. This shows that gender and SES factors have a combined effect on the effect of metacognitive factors on reading performance. However, when the effects of SES and gender are controlled together, the use of metacognitive strategies continued to be a significant predictor of reading success (Bilican \& Y1ldırım, 2014; Callan et al., 2016). 
Another result obtained from this study is that reading self-concept has a significant effect on the relationship between reading and metacognition in all groups. Moreover, students' perception of reading difficulty is a stronger factor than their perception of reading competence. The individual effect of motivational factors such as self-concept on metacognitive knowledge and reading achievement creates a common effect in the relationship of these two variables. It is possible to find similar results in the related literature (Kolić-Vehovec et al., 2014; Roeschl-Heils et al., 2003; Van Kraayenoord \& Schneider, 1999). For example, Roeschl-Heils et al. (2003) found that good readers have a better reading self-concept and utilize more diverse metacognitive strategies than poor readers. Accordingly, self-concept and metacognition allow to distinguish between good and poor students and are important predictors of reading. In this sense, in order for students with low reading performance to improve, they should acquire metacognitive strategies so that they have positive self-concept of reading (Van Kraayenoord \& Schneider, 1999). In addition, better metacognitive knowledge probably improves text comprehension, but also improves the perception of self-efficacy in reading, which then facilitates their positive attitude towards reading (especially recreational (Kolić-Vehovec et al., 2014).

An interesting result obtained from this study is that students' reading enjoyment levels do not have a significant effect on the relationship between reading and metacognition. Although the enjoyment of reading variables are associated with reading performance and metacognition, the emergence of such a results is remarkable for PISA Turkey sample. However, when effects of other student background factors are controlled, reading enjoyment and the use of metacognitive control strategies in Hong Kong sample, which has high PISA reading performance, increases their reading performance (Lau \& Ho, 2016). This indicates that successful readers enjoy reading and utilize a wide range of metacognitive strategies. The fact that reading enjoyment mediates gender differences (Chiu \& McBride-Chang, 2006) and is an important predictor of reading (Koyuncu \& Firat, 2020) makes it important to examine the role of this variable in the relationship between metacognition and reading.

\section{Conclusions, limitations, and suggestions}

In this study, it was found that SES and gender moderate the effect of metacognition on reading performance. Therefore, the effect of these two factors should be taken into consideration in the research and applications to be made. In addition, males should be encouraged and motivated to participate in reading activities and read different kind of reading materials at home and school in order to reduce the effect SES and gender differences. In this context, since training on metacognitive strategies increases reading achievement (Michalsky, Mevarech, \& Haibi, 2009), integrating metacognitive strategies instruction in school curriculum (Wu \& Peng, 2017) and encouraging reading engagement (Froiland \& Oros, 2013) could possibly be other important suggestions.

In light of the study results, it can be suggested that direct metacognitive strategy teaching should address especially males and students with varying socioeconomic disadvantages. In this context, strategy teaching can be added to reading courses given in the curriculum. In addition, this can have a place both in teacher training programs and in-service training given to the teachers. Those programs should also include metacognitive strategy instruction to develop students' reading comprehension skills which are directly related to success in other fields such as mathematics and science.

This study is limited to PISA 2018 Turkey sample, PISA reading cognitive tests and student questionnaires. Similar studies could possibly be carried out in different samples from 
different countries, with different assessments and data types and their results can be compared with the results of the present study. The reading enjoyment and self-concept of reading variables were added to the models. In the studies to be conducted, different variables at the school and student levels can be included in the models as covariates.

\section{References}

Akyol, G., Sungur, S., \& Tekkaya, C. (2010). The contribution of cognitive and metacognitive strategy use to students' science achievement. Educational Research and Evaluation, 16(1), 1-21.

Anastasiou, D., \& Griva, E. (2009). Awareness of reading strategy use and reading comprehension among poor and good readers. Elementary Education Online, 8(2), 283-297.

Artelt, C., Schiefele, U. \& Schneider, W. (2001). Predictors of reading. European Journal of Psychology of Education, 16(3), 363-383.

Asparouhov,T. (2005). Sampling weights in latent variable modeling. Structural Equation Modeling, 23, 411-434.

Asparouhov, T., \& Muthén, B. (2010). Resampling methods in Mplus for complex survey data. Structural Equation Modeling, 14(4), 535-569.

Bembenutty, H. (2007). Self-regulation of learning and academic delay of gratification: Gender and ethnic differences among college students. Journal of Advanced Academics, 18(4), 586-616.

Best, R. M., Floyd, R. G., \& Mcnamara, D. S. (2008). Differential competencies contributing to children's comprehension of narrative and expository texts. Reading Psychology, 29(2), 137-164.

Bilican, S., \& Yildırım, Ö. (2014). The effects of approaches to learning on student's reflective and evaluative reading performance in Turkey: The results from PISA 2009. Procedia-Social and Behavioral Sciences, 116, 2437-2442.

Brown, T. A. (2015). Confirmatory factor analysis for applied research (2nd ed.). New York: Guilford.

Calet, N., López-Reyes, R., \& Jiménez-Fernández, G. (2020). Do reading comprehension assessment tests result in the same reading profile? A study of Spanish primary school children. Journal of Research in Reading, 43(1), 98-115.

Callan, G. L., Marchant, G. J., Finch, W. H., \& German, R. L. (2016). Metacognition, strategies, achievement, and demographics: Relationships across countries. Educational Sciences: Theory \& Practice, 16(5).

Callan, G. L., Marchant, G. J., Finch, W. H., \& Flegge, L. (2017). Student and school SES, gender, strategy use, and achievement. Psychology in the Schools, 54(9), 1106-1122.

Chen F. F. (2008). What happens if we compare chopsticks with forks? The impact of making inappropriate comparisons in cross-cultural research. Journal of Personality and Social Psychology, 95, 1005-1018.

Chiu, M. M., Chow, B. W. Y., \& Mcbride-Chang, C. (2007). Universals and specifics in learning strategies: Explaining adolescent mathematics, science, and reading achievement across 34 countries. Learning and Individual Differences, 17(4), 344365.

Chiu, M. M., \& McBride-Chang, C. (2006). Gender, context, and reading: A comparison of students in 43 countries. Scientific Studies of Reading, 10(4), 331-362.

Chuy, M., \& Nitulescu, R. (2013). PISA 2009: Explaining the gender gap in reading through reading engagement and approaches to learning. Research paper. Toronto: Council 
of Ministers of Education, Canada (CMEC) and Human Resources and Skills Development Canada (HRSDC).

Cohen, J. (1988). Statistical power analysis for the behavioral sciences (2nd ed.). Hillsdale, NJ: Erlbaum.

Enders, C. K., \& Mansolf, M. (2018). Assessing the fit of structural equation models with multiply imputed data. Psychological Methods, 23(1), 76-93.

Fraenkel, J. R., \& Wallen, N. E. (2006). How to design and evaluate research in education ( $6^{\text {th }}$ edition). New York: McGraw-Hill.

Froiland, J. M., \& Oros, E. (2014). Intrinsic motivation, perceived competence and classroom engagement as longitudinal predictors of adolescent reading achievement. Educational Psychology, 34(2), 119-132.

Geldhof, G. J., Preacher, K. J., \& Zyphur, M. J. (2014). Reliability estimation in a multilevel confirmatory factor analysis framework. Psychological Methods, 19(1), 72-91.

Gülleroğlu, D., Bilican, S., \& Demirtaşlı, N. (2014). The prediction of Turkish students' reading literacy skills by SES related variables for PISA 2003-2006-2009. Ankara University, Journal of Faculty of Educational Sciences, 47(2), 201-222.

İnce, M., \& Gözütok, F. D. (2018). Effect of parental education and home educational resources to student' results of PISA reading skills test. Elementary Education Online, 17(2), 947- 958.

Kendeou, P., Van Den Broek, P., Helder, A., \& Karlsson, J. (2014). A cognitive view of reading comprehension: Implications for reading difficulties. Learning Disabilities Research \& Practice, 29(1), 10-16.

Kim, W., Linan-Thompson, S., \& Misquitta, R. (2012). Critical factors in reading comprehension instruction for students with learning disabilities: A research synthesis. Learning Disabilities Research \& Practice, 27(2), 66-78.

Kolić-Vehovec, S., Rončević Zubković, B., \& Pahljina-Reinić, R. (2014). Development of metacognitive knowledge of reading strategies and attitudes toward reading in early adolescence: The effect on reading comprehension. Psihologijske Teme, 23(1), 77-98.

Kotte, D., Lietz, P., \& Lopez, M. M. (2005). Factors influencing reading achievement in Germany and Spain: Evidence from PISA 2000. International Education Journal, 6(1), 113-124.

Koyuncu, İ., \& Firat, T. (2020). Investigating reading literacy in PISA 2018 assessment. International Electronic Journal of Elementary Education, 13(2), 263275.

Lau, K. L., \& Chan, D. W. (2003). Reading strategy use and motivation among Chinese good and poor readers in Hong Kong. Journal of Research in Reading, 26(2), 177-190.

Lau, K. L., \& Ho, E. S. C. (2016). Reading performance and self-regulated learning of Hong Kong students: What we learnt from PISA 2009. The Asia-Pacific Education Researcher, 25(1), 159-171.

Lee, Y. H., \& Wu, J. Y. (2013). The indirect effects of online social entertainment and information seeking activities on reading literacy. Computers \& Education, 67, 168177.

Lim, H. J., \& Jung, H. (2019). Factors related to digital reading achievement: A multi-level analysis using international large scale data. Computers \& Education, 133, 82-93.

Lynn, R., \& Mikk, J. (2009). Sex differences in reading achievement. TRAMES: A Journal of the Humanities \& Social Sciences, 13(63/58), 1, 3-13.

Mak, S. K., Cheung, K. C., Soh, K., Sit, P. S., \& Ieong, M. K. (2017). An examination of student-and across-level mediation mechanisms accounting for gender differences in reading performance: a multilevel analysis of reading engagement. Educational Psychology, 37(10), 1206-1221. 
Mansolf, M., Jorgensen, T. D., \& Enders, C. K. (2020). A multiple imputation score test for model modification in structural equation models. Psychological Methods, 25(4), 393411.

Marks, G. N. (2008). Accounting for the gender gaps in student performance in reading and mathematics: Evidence from 31 countries. Oxford Review of Education, 34(1), 89-109.

McHardy, J., Chapman, E., \& O’Neill, M. (2021). What strategies do less-skilled adult readers use to read words, and how aware are they of these strategies? Adult Education Quarterly, 71(1), 73-89.

Memon, M. A., Cheah, J. H., Ramayah, T., Ting, H., Chuah, F., \& Cham, T. H. (2019). Moderation analysis: Issues and guidelines. Journal of Applied Structural Equation Modeling, 3(1), 1-11.

Michalsky, T., Mevarech, Z. R., \& Haibi, L. (2009). Elementary school children reading scientific texts: Effects of metacognitive instruction. The Journal of Educational Research, 102(5), 363-376.

Mokhtari, K., \& Reichard, C. A. (2002). Assessing students' metacognitive awareness of reading strategies. Journal of Educational Psychology, 94(2), 249-259.

Moll, K., Kunze, S., Neuhoff, N., Bruder, J., \& Schulte-Körne, G. (2014). Specific learning disorder: Prevalence and gender differences. PLoS one, 9(7), e103537.

Muthén, L.K. and Muthén, B.O. (1998-2012). Mplus user's guide (7 $7^{\text {th }}$ ed.). Los Angeles, CA: Muthén \& Muthén.

OECD (2010). PISA 2009 results: learning to learn Student engagement, strategies and practices (Vol III) http://dx.doi.org/10.178/9789264083943.

OECD (2019). PISA 2018 assessment and analytical framework. Paris: OECD Publishing. https://doi.org/10.1787/b25efab8-en

OECD (n.d.). PISA 2018 Rechnical Rort. https://www.oecd.org/pisa/data/pisa2018technicalreport/

Pressley, M. (2002). Metacognition and self-regulated comprehension. In A. E. Farstrup \& S. J. Samuels (Eds.), What research has to say about reading instruction (pp. 291-309). Newark, DE: International Reading Association.

Rajchert, J. M., Żułtak, T., \& Smulczyk, M. (2014). Predicting reading literacy and its improvement in the Polish national extension of the PISA study: The role of intelligence, trait-and state-anxiety, socio-economic status and school-type. Learning and Individual Differences, 33, 1-11.

Roeschl-Heils, A., Schneider, W., \& van Kraayenoord, C. E. (2003). Reading, metacognition and motivation: A follow-up study of German students in grades 7 and 8. European Journal of Psychology of Education, 18(1), 75-86.

Rogiers, A., Van Keer, H., \& Merchie, E. (2020). The profile of the skilled reader: An investigation into the role of reading enjoyment and student characteristics. International Journal of Educational Research,99, 101512. https://doi.org/10.1016/j.ijer.2019.101512

Rutter, M., Caspi, A., Fergusson, D., Horwood, L. J., Goodman, R., Maughan, B., ... \& Carroll, J. (2004). Sex differences in developmental reading disability: New findings from 4 epidemiological studies. Jama, 291(16), 2007-2012.

Säälik, Ü. (2015). Reading performance, learning strategies, gender and school language as related issues-PISA 2009 findings in Finland and Estonia. International Journal of Teaching and Education, 3(2), 17-30.

Säälik, Ü., Nissinen, K., \& Malin, A. (2015). Learning strategies explaining differences in reading proficiency. Findings of Nordic and Baltic countries in PISA 2009. Learning and Individual Differences, 42, 36-43. 
Sencibaugh, J. (2007). Meta-analysis of reading comprehension interventions for students with learning disabilities: Strategies and implications. Reading Improvement, 44(1), 622.

Shala, A., \& Grajcevci, A. (2018). Kosovo's low performance in PISA 2015: An explanation from a socioeconomic perspective. Educational Process: International Journal, 7(1), 48-59.

Sheorey, R., \& Mokhtari, K. (2001). Differences in the metacognitive awareness of reading strategies among native and non-native readers. System, 29(4), 431-449.

Sideridis, G. D., Mouzaki, A., Simos, P., \& Protopapas, A. (2006). Classification of students with reading comprehension difficulties: The roles of motivation, affect, and psychopathology. Learning Disability Quarterly, 29(3), 159-180.

Stapleton, L. M. (2008). Variance estimation using replication methods in structural equation modeling with complex sample data. Structural Equation Modeling: A Multidisciplinary Journal, 15(2), 183-210.

Solheim, O. J., \& Lundetræ, K. (2018). Can test construction account for varying gender differences in international reading achievement tests of children, adolescents and young adults? A study based on Nordic results in PIRLS, PISA and PIAAC. Assessment in Education: Principles, Policy \& Practice, 25(1), 107-126.

Torppa, M., Eklund, K., Sulkunen, S., Niemi, P., \& Ahonen, T. (2018). Why do boys and girls perform differently on PISA Reading in Finland? The effects of reading fluency, achievement behaviour, leisure reading and homework activity. Journal of Research in Reading, 41(1), 122-139.

van Bergen, E., Vasalampi, K., \& Torppa, M. (2020). How are practice and performance related? Development of reading from age 5 to 15. Reading Research Quarterly. Advance online publication. doi:10.1002/rrq.309

van den Broek, P., \& Espin, C. A. (2012). Connecting cognitive theory and assessment: Measuring individual differences in reading comprehension. School Psychology Review, 41(3), 315-325.

Van Kraayenoord, C. E., \& Schneider, W. E. (1999). Reading achievement, metacognition, reading self-concept and interest: A study of German students in grades 3 and 4. European Journal of Psychology of Education, 14(3), 305-324.

Vázquez-Cano, E., la Calle-Cabrera, D., María, A., Hervás-Gómez, C., \& López-Meneses, E. (2020). Socio-family context and its influence on students' PISA reading performance scores: Evidence from three countries in three continents. Educational Sciences: Theory and Practice, 20(2), 50-62.

Wanzek, J., Vaughn, S., Scammacca, N. K., Metz, K., Murray, C. S., Roberts, G., \& Danielson, L. (2013). Extensive reading interventions for students with reading difficulties after grade 3. Review of Educational Research, 83(2), 163-195.

$\mathrm{Wu}$, J. Y. (2014). Gender differences in online reading engagement, metacognitive strategies, navigation skills and reading literacy. Journal of Computer Assisted Learning, 30(3), 252-271.

Wu, J. Y., \& Peng, Y. C. (2017). The modality effect on reading literacy: Perspectives from students' online reading habits, cognitive and metacognitive strategies, and web navigation skills across regions. Interactive Learning Environments, 25(7), 859-876.

Yuan, K.-H., Yang-Wallentin, F., \& Bentler, P. M. (2012). ML versus MI for missing data with violation of distribution conditions. Sociological Methods \& Research, 41(4), 598-629. 